\title{
What does a family environment mean within hospitality establishments?
}

\section{Tracy Harkison}

\author{
Dr Tracy Harkison is a \\ senior lecturer in \\ hospitality at Auckland \\ University of \\ Technology, New \\ Zealand. Her research \\ passions are hospitality \\ education, the cruise \\ industry and the co- \\ creation of luxury \\ accommodation \\ experiences. This has \\ resulted in the \\ completion of her $\mathrm{PhD}$ \\ thesis on how the \\ luxury accommodation \\ experience is created.
}

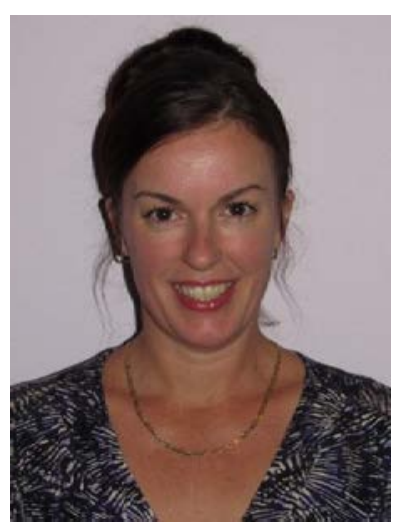

The exclusion of children from hospitality establishments is not new. Not all cultures or properties exclude children, but the cultivation and advertisement of a family environment at properties that do is a topic worthy of further consideration.

Some luxury properties are projecting a family environment while excluding children, which proposes a new definition of what a 'family environment' means and speculation about how such properties achieve this environment. The traditional view of 'family' has changed over time, and what is defined as family has also changed. One of these changes is that 'family' has morphed into 'families' in order to encompass new perceptions of the composition of the 'family' [1]. In addition, in many cultures, for example Italian, East Asian and Māori, the extended family rather than the traditional nuclear family is considered the basic unit [2]. The decrease or demise of the nuclear family is accredited to the rise in divorce rates, which has resulted in new forms of family units being formed. However, even though families are splitting and reforming after divorce, linkages through children remain [3]. The term 'families' is commonly defined as 'multigenerational social groups' comprised of at least one child and one adult [4].

While conducting interpretivist research on the creation of luxury accommodation experiences, qualitative data were collected from interviews with 81 participants (managers, employees and guests) at six luxury properties in New Zealand. Out of the six properties (classified as three luxury hotels and three luxury lodges), one did not accommodate children (a luxury lodge). Findings of the research revealed the theme of 'family' as important to all of the properties, even the property that was 'childfree'. This raises the question of whether children need to be present before a 'family environment' can be experienced within those hospitality establishments.

All the managers and employees interviewed in the research felt that guests wanted the feeling of being surrounded by family or of being part of a family. Managers and employees acknowledged that in lodges there is a smaller number of service personnel and, at the same time, a higher staff to guest ratio. The service personnel depend on each other and develop close teams, which are like families, in order to produce an outstanding experience for their guests. Managers and employees are closer to their guests in lodges due to guests dining on the premises two if not three times in the day, and managers often dine with 
the guests in their capacity as hosts, enabling them to build relationships with guests by engaging in conversation during these times. Guests, themselves, felt that staff treated them like family or made them feel part of the lodge family. They also commented that there was a feeling of family between the managers and staff and that they displayed those family bonds.

It has been suggested that the exclusion of children from some hospitality establishments is perhaps so they can concentrate on the niche market of 'adultonly'. Advantages of this focus are that it is not necessary to provide amenities and activities that are targeted at children and a premium price can be charged for the exclusivity of being an 'adult-only' establishment. Adult-only hotels can be dated back to the 1960s when Club Med was targeting singles [5]. In the 1980s, the hotel chain Sandals started luring Americans to Mexico and the Caribbean with adult-only packages and specific catering for couples [5].

The research suggests that projecting a family environment is now being used by luxury accommodation providers as a metaphorical term about the intimate attention that can be co-created in the accommodation servicescape through accommodation staff forming 'special relationships' with their guests in order to personalise their service. In this light, perhaps it is time to reconsider the nature of family-oriented accommodation in the sector, and to investigate how properties offer a 'family-like' environment that makes customers feel 'part of the family' while excluding children.

\section{Corresponding author}

Tracy Harkison can be contacted at: tracy.harkison@aut.ac.nz

\section{References}

(1) Dumon, W. The Situation of Families in Western Europe: A Sociological Perspective. In The Family on the Threshold of the 21st Century; Dreman S, Ed.; Lawrence Erlbaum Associates: London, 1997; chapt. 11.

(2) Robinson, E. Refining our Understanding of Family Relationships. Family Matters $2009,82,5-7$.

(3) Schänzel, H.A.; Yeoman, I. Trends in Family Tourism. Journal of Tourism Futures 2015, 1(2), 141-147. https://doi.org/10.1108/JTF-12-2014-0006

(4) Schänzel, H.A. Whole-Family Research: Towards a Methodology in Tourism for Encompassing Generation, Gender, and Group Dynamic Perspectives. Tourism Analysis 2010, 15(5), 555-569. https://doi.org/10.3727/108354210X12889831783314

(5) Divac, N. These German Vacationers Don't Take Kindly to the Kinder - Youngsters are Verboten as Hotels Seek Tranquility for Guests; No Cannonballs in Pool. Wall Street Journal, Feb 1, 2016; https://www.wsj.com/articles/for-these-german-vacationers-kidsare-verboten-1454288459 (accessed Mar 20, 2017). 